$\mathbb{P}$ periodica polytechnica

Civil Engineering

$55 / 2(2011) 117+128$

doi: 10.3311/pp.ci.2011-2.04

web: http://www.pp.bme.hu/ci

(C) Periodica Polytechnica 2011

RESEARCH ARTICLE

\section{Effects influencing the compressive strength of a solid, fired clay brick}

\author{
Anita Fódi
}

Received 2011-01-03, accepted 2011-03-01

\section{Abstract}

The aim of the paper was to analyze the effect of the different influencing factors on the compressive strength of a solid, clay brick. The effect of the surface polishing, the height, width and length of the specimens, the type of the sampling (drilled or cut) and the effect of the production technology were studied. Though being the moisture content of the specimen an important factor, it was not examined herein. More than 110 brick specimens were tested using two different types of measuring procedures: standard (destructive) compressive tests and Schmidt hammer (non-destructive) tests were carried out. Formulae were proposed for determining the normalized mean compressive strength from every possible type of specimens that were adequate for testing in case of this type of unit. It was found that the behaviour of the brick is orthotropic. It was proved that the effect of the height of the specimen has the most significant effect on the compressive strength. A linear relationship was found between the normalized mean compressive strength and the Young's modulus of the brick in each direction.

\section{Keywords}

solid clay brick · compressive strength $\cdot$ experimental investigation · size effect · Young's modulus

\section{Acknowledgement}

The author would like to express her grateful thanks to the colleagues in the Laboratory of the Budapest University of Technology and Economics and Wienerberger Ltd for offering materials and subsidy. This work is connected to the scientific program of the "Development of quality-oriented and harmonized $R+D+I$ strategy and functional model at BME" project. This project is supported by the New Hungary Development Plan (Project ID: TÁMOP-4.2.1/B-09/1/KMR-2010-0002).

\section{Anita Fódi}

Budapest University of Technology and Economics, Department of Structural Engineering, H-1111 Budapest, Bertalan L. 2, Hungary

e-mail: fodi@vbt.bme.hu

\section{Notation}

$f_{b, 65}$ the compressive strength of the brick specimen of $65 \mathrm{~mm}$ height $\left[\mathrm{N} / \mathrm{mm}^{2}\right]$

$A_{\text {loaded }}$ the loaded area $\left[\mathrm{mm}^{2}\right]$

$h$ the height of the specimen [mm]

$f_{b}^{*}$ the compressive strength of the specimen of $100 \mathrm{~mm} \times 100$ $\mathrm{mm}$ loaded area $\left[\mathrm{N} / \mathrm{mm}^{2}\right]$

$f_{b}$ the normalized mean compressive strength of the brick $\left[\mathrm{N} / \mathrm{mm}^{2}\right]$

$\delta$ the shape/conversion factor that is suggested to calculate the normalized mean compressive strength of a masonry unit according to [1]

$R_{i}$ the rebound value of the Schmidt hammer tests

$v$ the smaller size of the loaded area of the brick (the width of the brick) [mm]

\section{Introduction}

The determination of the compressive strength of the brick is not only important because it is necessary for the calculation of the compressive strength of the masonry but also it can be applied for determining the Young's modulus of the brick. The elastic modulus of the masonry is expressed in the function of the compressive strength of the masonry. For defining the compressive strength of the masonry Eurocode 6 [2] suggests using the normalized mean compressive strength that is the compressive strength of a unit with the dimensions of $100 \mathrm{~mm} \times 100 \mathrm{~mm}$ $\times 100 \mathrm{~mm}$ in case of air-dried condition.

The normalized mean compressive strength is hard to be measured. For most of the bricks, the size of the unit makes it impossible to determine the strength of the brick directly. The standard MSZ EN 772-1:2000 [1] does not allow to investigate compressive strength on a sample that has a height/smaller length ratio smaller than 0.4 or if the height of the specimen is smaller than $40 \mathrm{~mm}$. Therefore, in case of units with small height, samples have to be cut or the standard suggests applying multiple samples. Large units are appropriate for cutting cubic samples of 
$10 \mathrm{~cm}$ height. The standard [1] allows putting more bricks on each other. This raises the issue of contact, thus in this paper it is intended to be avoided.

The surface of the brick should be plane; the number of the tested specimens should be at least 6 . A further problem of the investigation of the strength is that brick size tolerance can be $6 \mathrm{~mm}$ in $65 \mathrm{~mm}$. Most of the bricks are too flat to investigate the strength directly. The standard [1] suggests determining the mean value of the compressive strength of six bricks in real sizes and then calculating the effect of the dimensions of the brick. For the normalized mean compressive strength the mean compressive strength has to be multiplied by a shape factor. This factor takes into account only the height and the smaller loaded side of the brick. The compressive strength of the brick can depend strongly on the production technology. The amount of additional sawdust, the splitting process and the firing temperature, the restraint effect of the platens, the height and shape of the specimen can have an effect on the compressive strength. The size and shape of the loaded area can have an influence on the results. In addition, the moisture content of the specimen can also have an effect on the strength. In this paper the effect of the surface polishing, the height, width and length of the specimens, the type of the sampling and the effect of the production technology and the effect of the burn in were investigated on the compressive strength.

The novelty of this paper is the investigation of the influence of the effect of the production technology (effect of the direction of the loading), the effect of the surface polishing, the height, width and length of the specimens and the type of sampling (drilled or cut) on the compressive strength. The aim of the paper was to find a correlation between the compressive strength and the mentioned features. Instead of the time consuming method of the standard [1] a simple, quick determination (Schmidt hammer tests) could be appropriate for determining the normalized mean compressive strength.

\section{Motivations}

A comprehensive experimental investigation of the compressive strength of solid bricks was missing from the literature before. If the compressive strength of the brick is dependent on the type of the production technology then brick anisotropy can be assumed. The Eurocode 6 [2] does not contain the effect of the anisotropy.

The investigation of the effect of the loading direction on compressive strength is important in the following cases: 1 . when the unit is placed not only in the lengthwise direction of the brick into the wall (see for example [3] and [4]) or 2. it is built in lengthwise but loaded from the other direction (in case of retaining walls). 3. It is important in case of investigating the compressive strength of buildings, too. The solid clay brick being investigated herein is the most traditional brick type in Hungary. There are a lot of buildings in Budapest built at the 1900 's that are constructed from solid clay brick. This brick is built in the wall normally lengthwise, the height of the unit is $65 \mathrm{~mm}$ and as usual it is loaded on the $120 \mathrm{~mm} \times 250 \mathrm{~mm}$ area. The thickness of the wall is $120 \mathrm{~mm}$. In the case of buildings, the cores obtained by horizontal drilling from building always show the compressive strength of the other two directions.

\section{The production technology}

Throughout the world, there are two possible ways of brick producing: the brick can be formed either by extrusion or by moulding. The former is applied in case of clays with high level of plasticity. When the plasticity of the clay is lower, the latter procedure is used characteristically [5]. In this case the clay cake is filled into brick moulds, and then pressed.

In Hungary only the first technology is typical. First, the clay exploited from the clay field is transferred into the factory where it is smashed with additional water and sawdust. After mixing it is pressed into a machine, and upon extrusion a column arises that is split into brick pieces. The raw bricks are conveyed into the drier where the bricks lose the majority of their moisture content under $40-100{ }^{\circ} \mathrm{C}$. Then units are transferred into the brick burning oven, where they are fired and afterwards burnished and bundled. That is the reason why visible shrinkage cracks can be seen on the surface of the most of the bricks.

Table 1 shows the results of a survey of the Brick Institute of America for the bricks in the United States. It shows that the compressive strength of the brick depends strongly on the production technology (extruded or moulded).

Tab. 1. Effect of the production method [6]

\begin{tabular}{cccc}
\hline Type of production & $\begin{array}{c}\text { Mean value of } \\
\text { the } \\
\text { compressive } \\
\text { strength } \\
{\left[\mathrm{N} / \mathrm{mm}^{2}\right]}\end{array}$ & $\begin{array}{c}\text { Standard } \\
\text { deviation of the } \\
\text { compressive } \\
\text { strength } \\
{\left[\mathrm{N} / \mathrm{mm}^{2}\right]}\end{array}$ & $\begin{array}{c}\text { Coefficient of } \\
\text { variations (\%) }\end{array}$ \\
\hline Extruded & 77.9 & 30.8 & 39.5 \\
Moulded & 36.5 & 12.6 & 34.5 \\
\hline
\end{tabular}

The $\delta$ conversion factor of [1] can be applied in every loading direction. The factor contains the effect of the height and the smallest width of the unit. The factor orders higher strength to the bigger blocks, which is not always true. The height of the brick is defined as the dimension of the sample in the direction of the load applied. Therefore it is applicable by calculation of the normalized mean compressive strength in every direction of the units. The $\delta$ factor does neither contain the effect of the other dimension of the brick, nor the difference because of the production direction. Most bricks contain holes that cause a smaller compressive strength. In case of solid bricks - if orthotropy does not exist -, the compressive strength after conversion due to size should be the same according to [1] and [2]. 


\section{Previous results of other researchers}

Most of the reports do not mention the way how the compressive strength of the brick was obtained, under what kind of circumstances. As a result of determination of the compressive strength, the most papers do not provide whether the value of the compressive strength is a mean value for the brick, or a mean value for a $10 \mathrm{~cm} \times 10 \mathrm{~cm} \times 10 \mathrm{~cm}$ unit. Even less publications contain empirical results for the determination of the relationship between the compressive strength and the Young's modulus of the brick. However, the Young's modulus of the masonry is given as the function of the compressive strength in few articles.

According to the work of Pate and Noble (1958) [7] the relationship between the elastic modulus and the compressive strength of the clay bricks is linear in case of low compressive strength. In case of higher compressive strength the Young's modulus increases exponentially. They determined the relationship between the firing temperature and the compressive strength of the brick and then between the firing temperature and Young's modulus. They found that proportionality exists between the two mechanical features (see Figure 11). However it was not defined which type of compressive strength (normalized or mean) was taken into account. Pate and Noble investigated the compressive strength of the brick only in one direction.

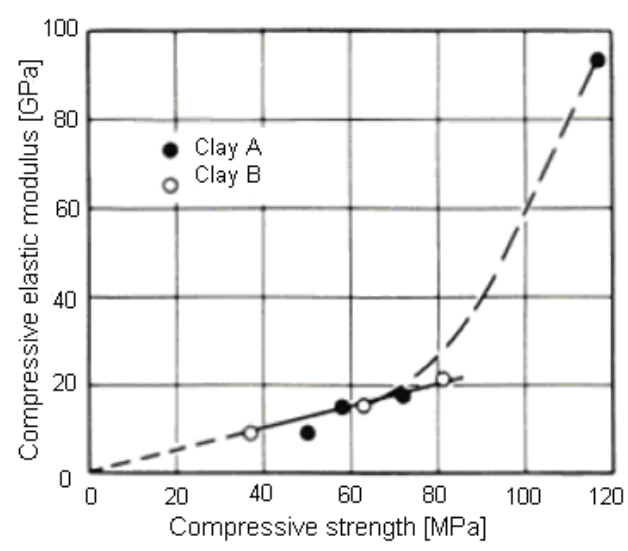

Fig. 1. Relationship between the Young's modulus and compressive strength [7]

Ayala (1998) [8] collected the compressive strength and the Young's moduluses of fired clay bricks, mortars and masonry walls for a statistical analysis. He investigated the connection between the Young's modulus and the compressive strength of the masonry units, mortar and masonry walls. The compressive strength of the mortar and the brick are normalized with respect to the thickness of the mortar, the height of the brick and the masonry wall. A direct proportionality was found between the compressive strength of the unit, mortar, and the masonry wall. The compressive strength was investigated only in one direction of the unit. As Figure 2 shows the results have an extremely high standard deviation.

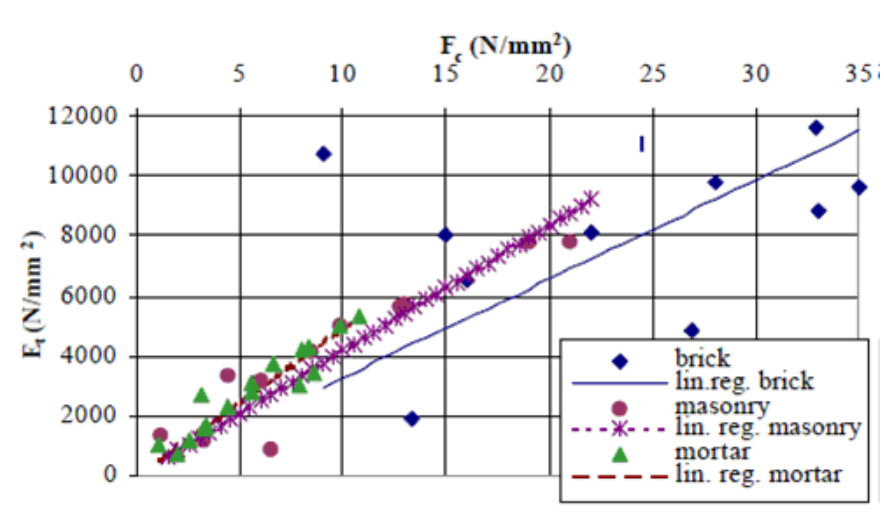

Fig. 2. Relationship between the Young's modulus and the compressive strength of the brick, mortar and masonry [8]

\section{Experimental program}

A comprehensive experimental investigation was worked out with testing of more than 110 specimens in order to determine the effect of the parameters mention below on the compressive strength of the brick, the normalized compressive strength and the Young's modulus of the brick. The dimensions of the masonry unit were $65 \mathrm{~mm} \times 120 \mathrm{~mm} \times 250 \mathrm{~mm}$. This type of brick can be built into the wall in every direction. For all types of investigation all the specimens originated from the same bundle, from the same manufacturer. The bricks were tested under airdried conditions. The maximum specimen size that could be obtained from this type of brick with a plane surface was a $5 \mathrm{~cm}$ $\times 5 \mathrm{~cm} \times 5 \mathrm{~cm}$ cubic sample. The smallest reasonable sample was analyzed, too.

18 specimens were investigated experimentally to determine the effect of the roughness of the surface, 45 for defining the influence of the length (loaded area) of the brick. 17 full size brick and 10 drilled cores were tested in order to determine the effect of the type of the sampling and the size of the brick and 24 specimens to investigate the anisotropy of the brick.

Two types of testing machines were applied in order to reach the ultimate loads in the $2 / 3$ part of the loading capacity of the machine for all types of specimens. In both cases the experiments were force-controlled. The velocity of the loading was applied that the ultimate load was reached in 1-2 minutes after beginning the loading. Both machine were jointed at the top and fixed at the bottom.

Schmidt hammer tests were worked out in order to determine the compressive strength in every direction with a nondestructive method.

The Young's modulus of the brick was measured by two methods: by strain gauges on the cylindrical, drilled samples and by inductive transducers on full size bricks. The applicability of the tests was controlled.

\section{Results}

\subsection{Effect of the production technology}

In order to investigate the effect of the anisotropy of the brick without the influence of the size effect it would be necessary 
to test bricks of the same sizes $(50 \mathrm{~mm} \times 50 \mathrm{~mm} \times 50 \mathrm{~mm})$ under the same circumstances. The biggest cubic specimen that could be reasonably formed from this type of brick is $50 \mathrm{~mm}$ $\times 50 \mathrm{~mm} \times 50 \mathrm{~mm}$. To examine the effect of the location of the tested specimens in the brick (the effect of burning in during the firing process) specimens were produced from the side and from the middle of the brick. Figure 3 shows the adjustment and nomination of the cut specimens. $\mathrm{S}$ indicates that the specimen originated from the side part of the brick, $\mathrm{M}$ indicates that it was situated in the middle of the brick.

For better identifiability of the effect of the production technology, the following directions are defined: $\mathrm{A}$ is the direction of extrusion (flatwise), B is the direction of cutting (the second shortest side) and $\mathrm{C}$ is lengthwise behaviour. Figure 4 shows the definition of the directions.

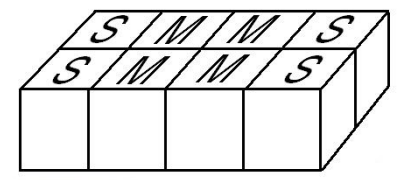

Fig. 3. Investigation of the effect of the location of the specimens within the brick

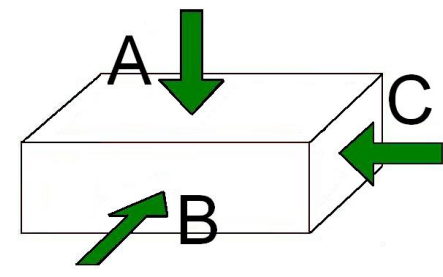

Fig. 4. The loading directions defined

Altogether 24 specimens were investigated, 8 pieces in each directions. The experiment brought the result that it has no significant effect on the compressive strength of the brick where the sample was situated in the brick. Table 2 presents that the compressive strength is different in each loading direction, the brick shows a clear orthotropic material behaviour.

A statistical analysis was carried out to prove that suspicion. As the standard deviations of the samples were not the same, a Welch's test could be applied to determine the existence of heterogeneity because of the different producing directions. Therefore, supposing the normal distribution of the strength of the samples it can be stated that the difference in compressive strength between the directions $\mathrm{A}$ and $\mathrm{B}$ exists with a probability of more than $99.5 \%$. Between the directions B and C it is $94.3 \%$, and between the directions $\mathrm{A}$ and $\mathrm{C}$ it is at least $95.8 \%$. (degrees of freedom in all cases approx. 14) Therefore, the difference between the loading direction A, B and C dependably exists; the brick shows an orthotropic material behaviour. This means that a difference of $30 \%$ and $16 \%$ in the compressive strength in case of this brick only occurs due to the investigated loading direction.

The experiments show that the samples are anisotropic and have a fibrous construction. The production technology of this type of brick leads to an orthotropy whose direction corresponds to the brick edges. That is the reason why an orthotropy of the brick could be assumed. The loading direction A corresponds to the direction of the extrusion. The brick has the highest compressive strength in this direction, which is an obvious fact because the degree of the compaction is the highest in this direction. In the direction $\mathrm{B}$, the compressive strength of the brick amounts to the smallest value. This direction corresponds to the direction of the splitting.

In this paper, every investigated sample is produced by the same manufacturer. The statements related to the degree of the orthotropy are true only for this production technology or for solid bricks that are produced by the same method. Every other statement is of general validity.

Looking at the values of the multiplicator given by [1] because of the size effect, it can be seen that the modification in the compressive strength caused by the multiplicator takes 45 $55 \%$. This reflects that the effect of the loading direction cannot be neglected in case of this brick type and this production technology if the effect of the height is taken into account.

\subsection{The effect of roughness of the surface}

In order to investigate the effect of the smoothness of the surface of the brick, specimens with raw and polished surfaces were investigated, respectively. The specimens were polished by a diamond saw. Table 3 shows the mean value of the compressive strength, the standard deviation and the coefficient of variation resulting from the tests of 7 specimens. All sizes of the bricks were the same.

Table 3 shows that the polishing process results in a $26 \%$ increase in the compressive strength; however, it is coupled with an increasing coefficient of variation. The standard [1] orders to carry out the compressive tests on polished bricks, however Table 3 shows that polishing increases the coefficient of variation and increases the mean value of the compressive strength. It is necessary to notice that to avoid local effects of the small bulges on the surface of the brick, thin carton layer was placed between the brick surface and the platens.

\subsection{Effect of the length of the loaded surface}

The effect of the extension of the loaded surfaces on the compressive strength bricks with full length, 3/4 length and 1/2 length were examined in Table 4. It contains the mean values of the compressive strength in case of the same number of samples.

Comparing the results, the difference in the mean values of the compressive strength of the full length and three-quarter length brick is only $7.59 \%$. The diagram of Figure 5 clearly shows that by decreasing the length of the brick, if the height and the width of the sample are constant, the coefficient of variation will increase extremely. In case of a loaded half length brick, the brick length is $125 \mathrm{~mm}$, being a bit longer than the other horizontal 
Tab. 2. Orthotropy of the brick measured on specimens of same sizes

\begin{tabular}{ccccc}
\hline Investigated direction & Number of samples & $\begin{array}{c}\text { Mean value of the } \\
\text { compressive strength } \\
{\left[\mathrm{N} / \mathrm{mm}^{2}\right]}\end{array}$ & $\begin{array}{c}\text { Standard deviation } \\
{\left[\mathrm{N} / \mathrm{mm}^{2}\right]}\end{array}$ & $\begin{array}{c}\text { Coefficient of variation } \\
{[\%]}\end{array}$ \\
\hline A & 8 & 29.32 & 5.17 & $17.63 \%$ \\
B & 8 & 20.70 & 4.57 & $22.06 \%$ \\
C & 8 & 24.64 & 4.72 & $19.13 \%$ \\
\hline
\end{tabular}

Tab. 3. Effect of the surface

\begin{tabular}{ccccc}
\hline Name of specimen & Number of samples & $\begin{array}{c}\text { Mean value of the } \\
\text { compressive strength } \\
{\left[\mathrm{N} / \mathrm{mm}^{2}\right]}\end{array}$ & $\begin{array}{c}\text { Standard deviation of } \\
\text { the compressive } \\
\left.\text { strength [N/mm }{ }^{2}\right]\end{array}$ & $\begin{array}{c}\text { Coefficient of variation } \\
{[\%]}\end{array}$ \\
\hline Raw surface & 7 & 35.10 & 1.14 & $3.25 \%$ \\
Polished surface & 7 & 44.22 & 5.35 & $12.10 \%$ \\
\hline
\end{tabular}

size of the brick. Thus, in case of this test the smaller horizontal dimension of the loaded area is the same, so it can be seen clearly that the compressive strength can depend on the other size of the specimen. That statement does not correspond to the application of the conversion factor. Therefore, any size of the loaded area has an effect on the compressive strength.

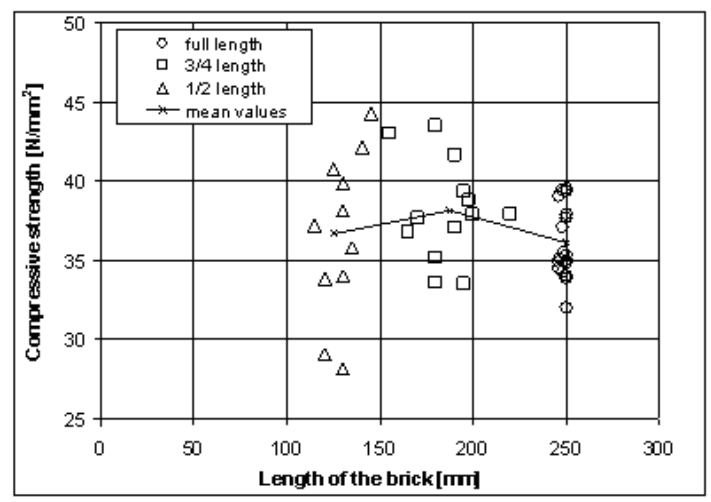

Fig. 5. Change in compressive strength according to the length of the brick in case of $65 \mathrm{~mm}$ high and $120 \mathrm{~mm}$ wide brick

That means if the lowest values of the compressive strength in Figure 5 are approached by a linear function or the whole assembly by a constant function, than

1 the compressive strength will depend only on the smaller width

2 it will depend linearly on the larger dimension of the loaded area in case of the same smaller width

3 it depends linearly on the extension of the loaded area

4 it does not depend on the loaded area.

Furthermore, Figure 5 shows that an optimal size of the specimen exists that results the maximal compressive strength of the brick. This phenomenon is known in case of the concrete. For this type of brick, the optimal size of the loading area that presents the maximum compressive strength is ca. $21000 \mathrm{~mm}^{2}$.
In case of investigating specimens with relatively small height, the size effect should be considered. Between the loading platens and the specimen's surface a friction exists. This frictional force tries to prevent the lateral deformation along the platens. That is the reason why the crack pattern of a small sample consists of an upper and lower triangle, and an undisturbed zone takes place only in the middle of the specimen. However, the height of this type of brick is only $65 \mathrm{~mm}$, therefore it is not possible to obtain higher specimens. It is not reasonably to investigate specimens with smaller than $40 \mathrm{~mm} \times 40 \mathrm{~mm}$ loaded surface, because it contains more or less cracks, than the brick, i.e. the representative volume of the brick is surely bigger than this size.

\subsection{Effect of the height of the samples}

In order to investigate the effect of the specimen's height and the type of the sampling, full size bricks were loaded in every direction, on the polished surface. The height is defined as the dimension in the loaded direction. The Table 5 contains the results measured. The values are not converted into the compressive strength of one direction.

It could be clearly observed that the failure mode was different in case of the different testing directions due to the different testing sizes. In case of investigating direction A, a typical compressive crushing could be observed. An elliptical compressed zone remained almost hurtless, and the other part of the brick got crushed. Figure $6 \mathrm{a}$ and $\mathrm{b}$ show the compressive failure of the direction A. In case of direction B, as it is not usual, horizontal crack occurred along the length of the brick and then the well known vertical splitting could be observed and a shear failure occurred. An upper and a lower triangular prism could be observed. Figure $7 \mathrm{~b}$ shows the two triangular prisms. In case of testing the direction $\mathrm{C}$, a compressive failure could be observed (Figure 8). 
Tab. 4. Effect of the length (loaded area) of the specimen

\begin{tabular}{ccccc}
\hline Name of specimen & Number of samples & $\begin{array}{c}\text { Mean value of the } \\
\text { compressive strength } \\
{\left[\mathrm{N} / \mathrm{mm}^{2}\right]}\end{array}$ & $\begin{array}{c}\text { Standard deviation of } \\
\text { the compressive } \\
\text { strength }\left[\mathrm{N} / \mathrm{mm}^{2}\right]\end{array}$ & $\begin{array}{c}\text { Coefficient of variation } \\
{[\%]}\end{array}$ \\
\hline Raw surface, full size & 11 & 35.66 & 2.31 & 6.49 \\
Raw surface, 3/4 length & 11 & 38.59 & 3.13 & 8.12 \\
Raw surface 1/2 length & 11 & 36.66 & 5.12 & 13.96 \\
\hline
\end{tabular}

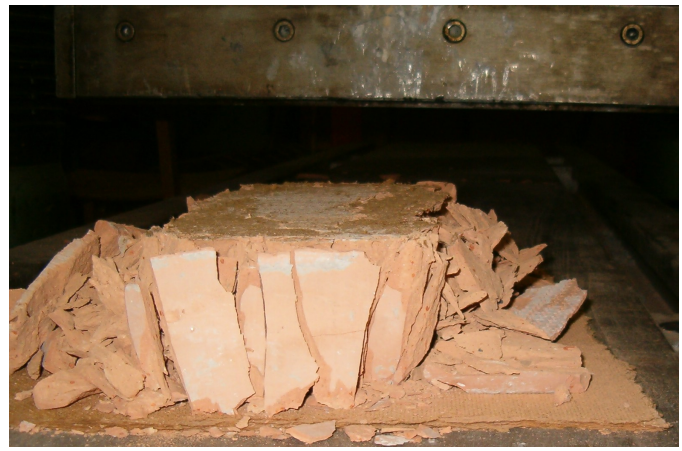

a)

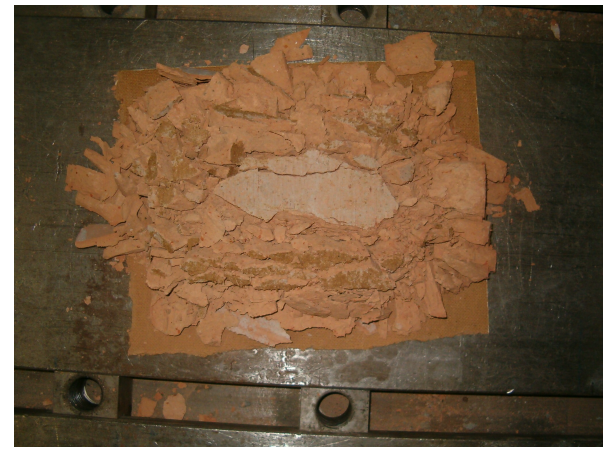

b)

Fig. 6. Crushing and vertical splitting in case of testing direction A (compressive failure)

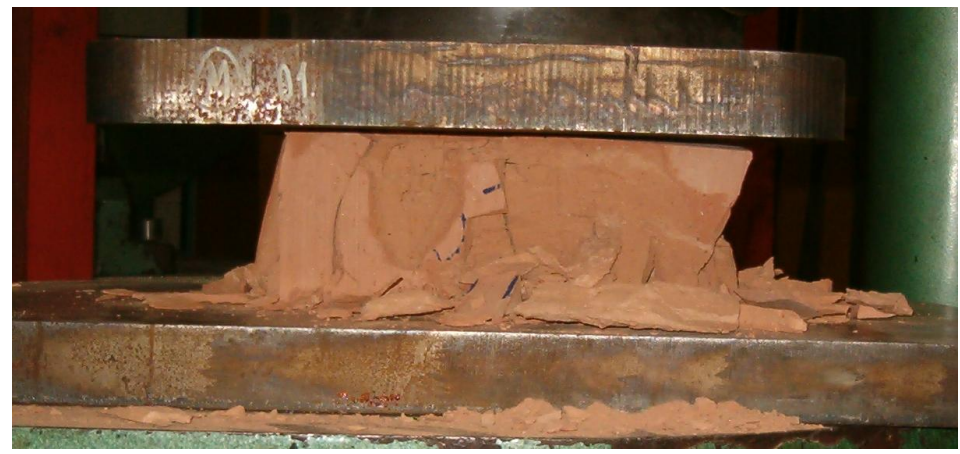

a)

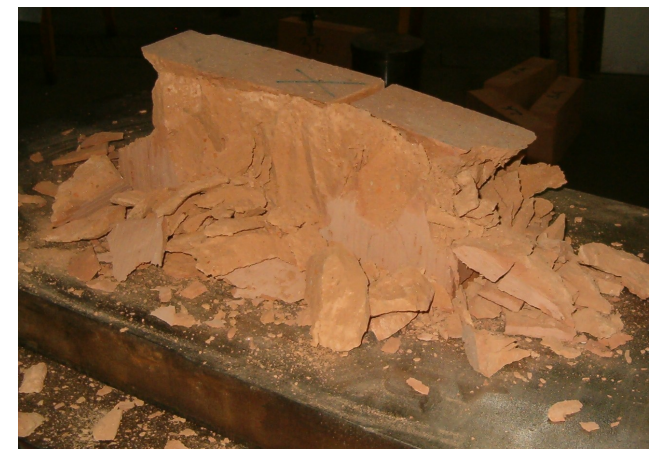

b)

Fig. 7. Shear failure in case of testing direction $B$

Tab. 5. Test results of the full size bricks

\begin{tabular}{|c|c|c|c|c|c|c|c|}
\hline Direction & $\begin{array}{l}\text { Number of } \\
\text { samples }\end{array}$ & $\begin{array}{l}\text { Smaller size } \\
\text { (width) [mm] }\end{array}$ & $\begin{array}{l}\text { Bigger size } \\
\text { (length) }[\mathrm{mm}]\end{array}$ & Height [mm] & $\begin{array}{c}\text { Mean value } \\
\text { of the } \\
\text { compressive } \\
\text { strength } \\
{\left[\mathrm{N} / \mathrm{mm}^{2}\right]}\end{array}$ & $\begin{array}{l}\text { Standard } \\
\text { deviation } \\
{\left[\mathrm{N} / \mathrm{mm}^{2}\right]}\end{array}$ & $\begin{array}{l}\text { Coefficient of } \\
\text { variation [\%] }\end{array}$ \\
\hline$A$ & 5 & $117.8-118.7$ & 246.5-251.0 & $55.6-56.3$ & 45.3 & 6.23 & 13.73 \\
\hline$B$ & 5 & $63.4-65.1$ & $246.2-246.9$ & $110.0-112.6$ & 16.73 & 4.76 & 28.45 \\
\hline C & 5 & $64.2-64.8$ & $118.6-119.3$ & $231.0-241.1$ & 10.48 & 2.26 & 21.56 \\
\hline
\end{tabular}




\subsection{Effect of the type of sampling}

Investigation of the compressive strength of samples with small diameters (drilled cores) is a characteristic testing method for concrete members. [9] investigated drilled cores of cylindrical spun-cast concrete elements. The cores were $85-95 \mathrm{~mm}$ height and all the specimens had a diameter of $60 \mathrm{~mm}$. [10] collects experiments for investigating the compressive strength of concrete with different sizes and shapes, and it emphasises that contradiction exists between the results of the researchers.

To investigate the effect of sampling, cylindrical samples of $44.5 \mathrm{~mm}$ diameter were drilled in 3 directions out of every brick. Only the height of the specimen changed. Every drilled sample was full of cracks or discontinuities, almost in every direction, because of shrinkage. No directivity could be observed. However, on the brick surface in loading direction A elliptical shrinkage cracks could be noticed. The drilled cores showed inhomogenity in every direction.

The results are shown in Table 6 . There were only a few samples investigated because it was hard to gain samples not broken during the coring process, especially in direction B.

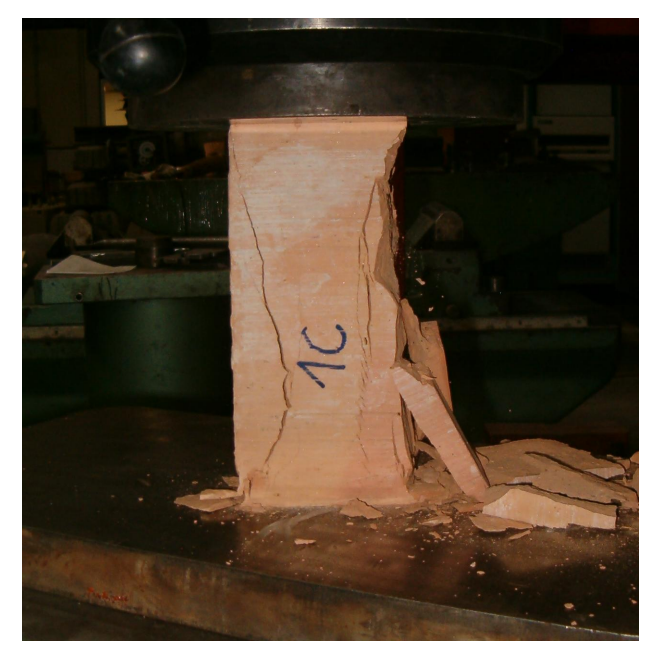

Fig. 8. Typical compressive failure in case of testing direction $\mathrm{C}$

Figure 9 shows that the failure modes were distinct in case of the different samples. If direction A was investigated, then, in every case, the compressive failure was crushing, or vertical splitting independent of the discontinuities that the sample contained. In testing direction B, the inhomogenity in the brick played a role. Half of the samples cracked at the location of the cracks, the other half suffered compressed crushing. In every case by testing direction $\mathrm{C}$ the brick cracked along the fault. After cracking at the discontinuity, the two parts of the samples remained almost hurtless.

\section{Consequences}

According to the experiments carried out, it turned out that a representative characterisation method for the compressive strength is rather the function of the loaded area than the function of the smaller width. The reason of this - as shown in Figure 5- is that for the same value of the smaller size results al-

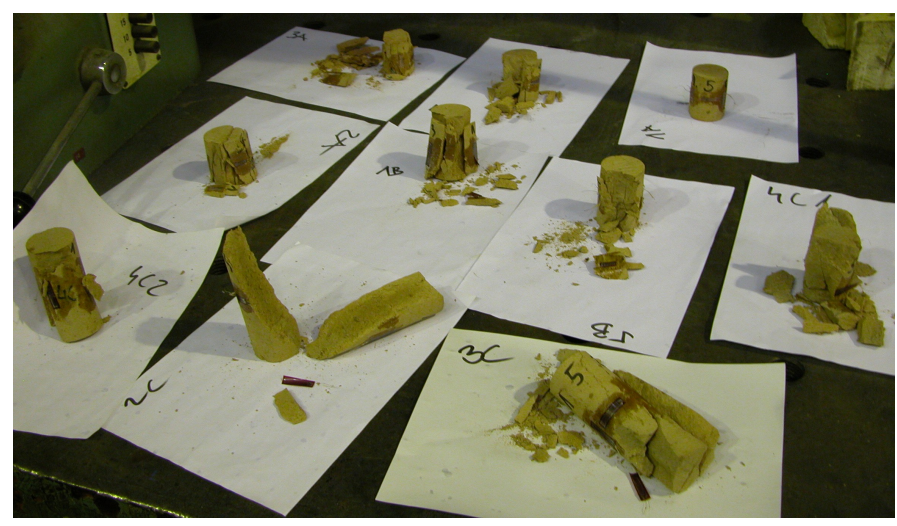

Fig. 9. Failures in case of testing drilled samples

most the same compressive strength, with bigger standard deviation. Two possibilities should be considered according to Figure 5. the compressive strength does not change with the loaded area if the width does not change. In this case the compressive strength depends only on the height and the smaller size of the specimen. The second possibility of approach by a linear function of the loaded area, for the lowest compressive strength values of the experimental results, thus the following formula can be obtained:

$$
f_{b, 65}=0.0003 A_{\text {loaded }}+24
$$

where $f_{b, 65}$ is the strength of the brick in $\mathrm{N} / \mathrm{mm}^{2}$ of $65 \mathrm{~mm}$ height, $A_{\text {loaded }}$ is the loaded area in $\mathrm{mm}^{2}$.

According to these two different approximations the measured compressive strength can be transformed into an equivalent compressive strength measuring on a $10 \mathrm{~cm} \times 10 \mathrm{~cm}$ loaded area. Figure 10 shows the compressive strength with the normalized area and with the unconverted area. All the mean values of the measured compressive strength of Figure 10 are transformed into the A-directional compressive strength.

Two curves can be drawn for the results. The lower curve signed by a thin dashed line represents the mean values of the compressive strength of the drilled and the highest one signed by a thin continuous line shows that of the rectangular samples of the full brick tests.

To the measured data of the brick tests, transformed into the compressive strength of direction A, curves can be fitted with linear regression by the least squares method. The equation of the regression curves with the untransformed area can be seen in the Figure 10

The equation of the regression curve for the results of the brick tests with the normalized area is:

$$
f_{b}^{*}=525 / h^{0.68}
$$

where $f_{b}^{*}$ is the compressive strength of the specimen of $10 \mathrm{~cm}$ $\times 10 \mathrm{~cm}$ loaded area and $h$ is the height of the specimen. The reliability of the relationship is with a correlation coefficient $R^{2}=0.96$. A similar, simple curve can be fitted to the results of 
Tab. 6. Experimental results for the drilled cylinders

\begin{tabular}{|c|c|c|c|c|c|}
\hline Direction & Diameter [mm] & Height [mm] & $\begin{array}{l}\text { Mean value of the } \\
\text { compressive } \\
\text { strength }\left[\mathrm{N} / \mathrm{mm}^{2}\right]\end{array}$ & $\begin{array}{l}\text { Standard deviation } \\
\text { of the compressive } \\
\text { strength }\left[\mathrm{N} / \mathrm{mm}^{2}\right]\end{array}$ & $\begin{array}{l}\text { Coefficient of } \\
\text { variation [\%] }\end{array}$ \\
\hline A & 44.4 & 58.8 & \multirow{4}{*}{29.84} & \multirow{4}{*}{9.17} & \multirow{4}{*}{30.74} \\
\hline A & 44.5 & 57.7 & & & \\
\hline A & 44.5 & 56.3 & & & \\
\hline A & 44.4 & 57.0 & & & \\
\hline B & 44.5 & 75.6 & \multirow{2}{*}{11.58} & \multirow{2}{*}{ - } & \multirow{2}{*}{ - } \\
\hline B & 44.5 & 66.2 & & & \\
\hline C & 44.4 & 130.1 & \multirow{4}{*}{10.41} & \multirow{4}{*}{2.34} & \multirow{4}{*}{22.48} \\
\hline C & 44.5 & 132.0 & & & \\
\hline C & 44.4 & 90.0 & & & \\
\hline C & 44.5 & 89.6 & & & \\
\hline
\end{tabular}

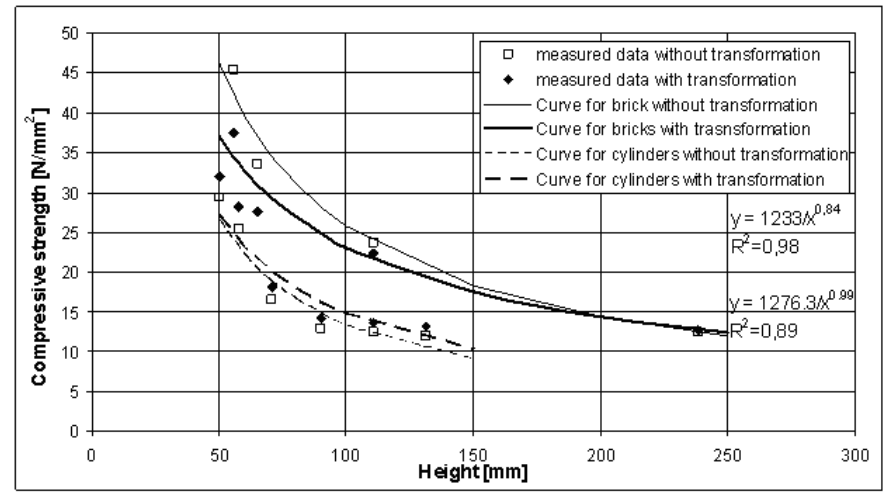

Fig. 10. Mean values of the compressive strength in the function of the height of the specimen with the equation of the untransformed curves

the drilled specimens and the cubic specimens with an equation of

$$
f_{b}^{*}=831 / h^{0.87} .
$$

The correlation coefficient is $R^{2}=0.83$.

It is worth mentioning that one curve can be fitted to all the data. In case of the measured normalized data the following equation can be obtained:

$$
f_{b}^{*}=521.3 / h^{0.72} \text {. }
$$

The correlation coefficient is $R^{2}=0.75$.

Supposing that the compressive strength of the brick depends on the height of the specimen and the smaller size of the loaded area only, then - if the results are compared to the suggestions of the Eurocode 6 -, Figure 11 could be derived. The continuous, almost parallel curves show the effect of the $\delta$ factor [1] on the compressive strength in case of different smaller size, $v$. If the normalized compressive strength is derived from the cubic samples according to [1], then the desired value is $25 \mathrm{~N} / \mathrm{mm}^{2}$. All the values and the mean values from the experiments are shown in the Figure 11. It shows that the height of the specimen has the biggest effect on the compressive strength of the brick. The values are not transformed into the equivalent area and they are transformed into the A directional compressive strength.

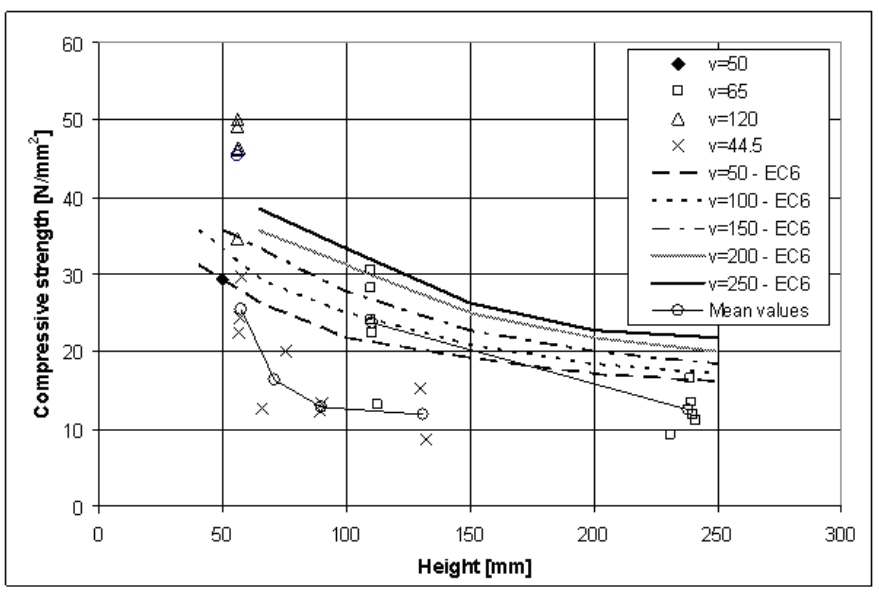

Fig. 11. The effect of height compared to the suggestion of the standard [1 (mean values and all the results)

In order to determine the function that makes possible to get the normalised mean compressive strength of every type of sample, a function is needed to be found. This process was made by linear regression with the least squares method.

As a first step, functions that are similar to the relationships given for concrete were investigated. For example [10] covers a lot of relationships of the compressive strength and the geometry of concrete specimens. The compressive strength of concrete is given as the function of the edge length of the cube, of the loaded area/volume and of the height/diameter ratio.

Figure 12 shows the experimental results of the compressive strength in the function of the loaded area/specimen volume ratio. Linear functions were defined for the brick and for the cylindrical specimens with a good correlation. All results are converted to the compressive strength of the direction A. The 
height/loaded area ratio does not conduce to a result.

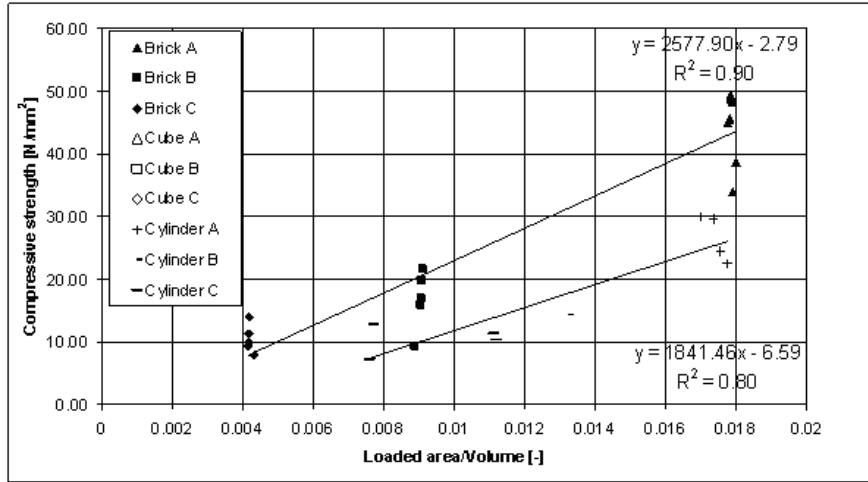

Fig. 12. The measured compressive strength in the function of the loaded area/volume of the specimens

If the compressive strength of the brick is a function of the ratio of the smaller size and the height of the specimen, Figure 13 can be derived. The smaller width is the diameter of the samples in case of the cylindrical samples. All data are transformed into the A-directional compressive strength

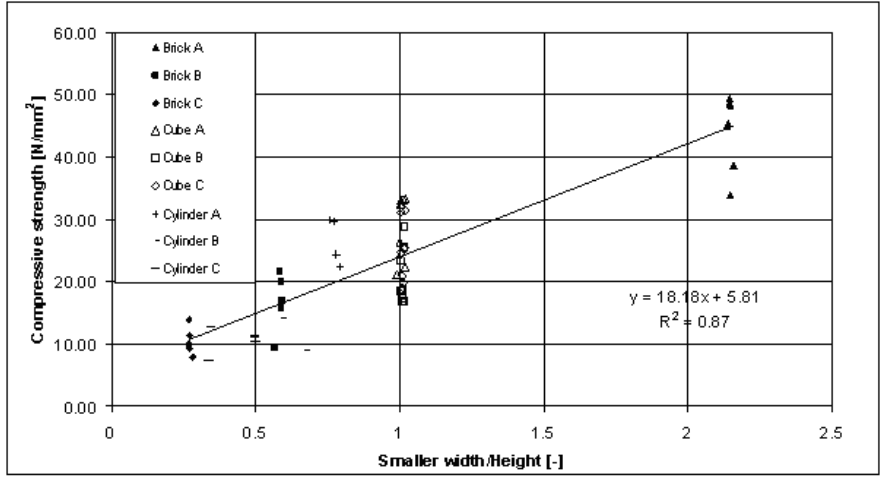

Fig. 13. The measured compressive strength in the function of the height/width of the specimen ratio

In case of investigating the cylindrical samples only the height has an effect on the compressive strength. The measured values can be seen in the function of the height in Figure 14 . The diagram shows the dependence of the compressive strength on the height in case of cylindrical samples.

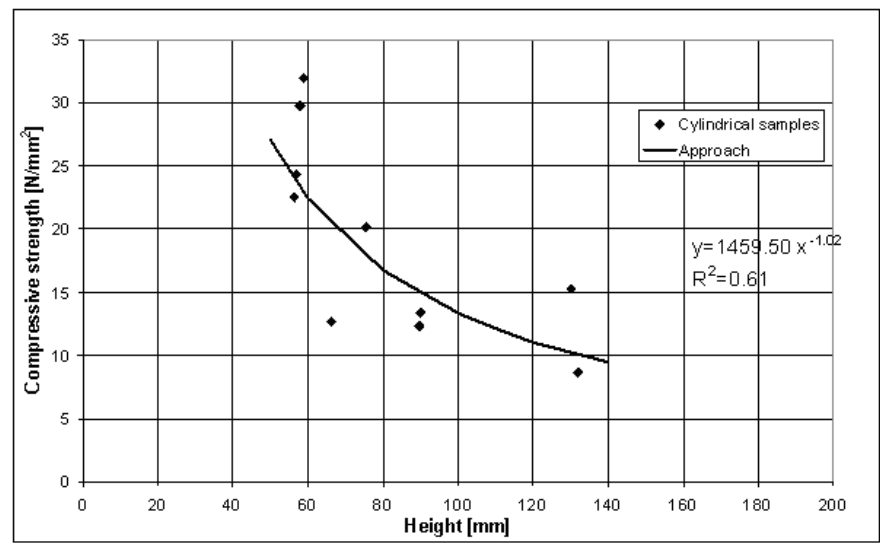

Fig. 14. The compressive strength in the function of the height for all results of the cylindrical samples
If the equation of Figure 14 is applied to convert the height of the specimen into $10 \mathrm{~cm}$ height, then the loaded area or the smaller size will be a function of the compressive strength. In case of the drilled samples, the compressive strength of the $100 \mathrm{~mm}$ high specimen is $13.31 \mathrm{~N} / \mathrm{mm}^{2}$. If each of the other samples is shown in the same diagram (see. Figure 15), then it can be seen that the coefficient of variations of the strength of the samples is relatively high (see Table 5 and 6. It is not reasonable to take the smaller size into account, as the standard deviation has bigger effect than the smaller size. It shows that the height of the specimen has the biggest effect on the compressive strength. Each of the results are converted into the A directional compressive strength.

Therefore, the compressive strength of the unit is inversely proportional to the height of the specimen. For the whole brick test the dashed line, for the cylindrical sample the continuous line of Figure 15 is suggested to take the effect of the height of the specimen into account.

In case of this brick, the normalised mean compressive strength in direction $\mathrm{A}$ is approx. $20-25 \mathrm{~N} / \mathrm{mm}^{2}$.

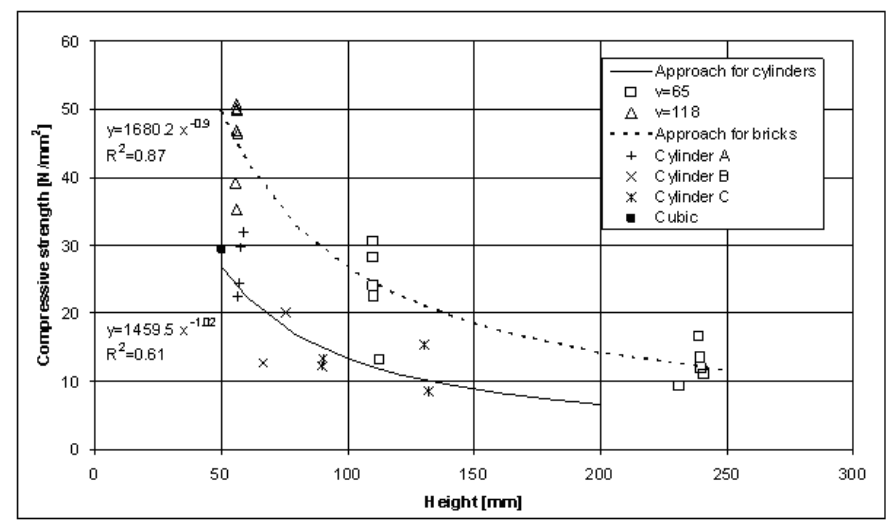

Fig. 15. Compressive strength in the function of the height in case of all experimental results

\section{Determination of the compressive strength of the brick by Schmidt hammer, type $\mathbf{N}$ (non-destructive test)}

According to the directive MI 15011-1988 [11] it is possible to determine the compressive strength of a brick by an $\mathrm{N}$ type Schmidt hammer. However, it is not known whether the strength obtained by Schmidt hammer is in conformity with the normalized mean compressive strength of Eurocode 6, or this testing method gives the compressive strength of a brick. The standard [1] does not dispose of the determination of the compressive strength of the brick by Schmidt hammer.

Rebound tests were carried out using Schmidt hammer, type $\mathrm{N}$ (two times 15 samples were examined). Full size bricks were investigated in directions $\mathrm{B}$ and $\mathrm{C}$. In the direction $\mathrm{A}$ it was not possible to measure because of technical reasons. The brick has to be pressed in order to prohibit the moving of the brick. It was determined that the value of the rebound index strongly depends on the hold-down force. Each measurement published here was 
carried out under $1.33 \mathrm{~N} / \mathrm{mm}^{2}$ compressive stress, applying horizontal beating directions.

Pál Gábory investigated the compressive strength of masonry by Schmidt hammer, type N. The MI directive [11] suggests applying the equation 10 in order to determine the compressive strength of a brick by Schmidt hammer, type $\mathrm{N}$ according to his work. Dulácska suggests a linear relationship (6) of these two parameters in [12]. In 2001, Dulácska, Józsa and Borosnyói modified the latter equation in [13], in case of investigating the compressive strength of bricks of old buildings. The modified equation (7) and equation (6) applies to horizontal beating directions. Dulácska [14] found in 2008 that the relationship between the rebound index and the compressive strength obtained by [11] has to be modified. He corrected the equation of Gábory (10) and suggested applying (8) in case of horizontal beating direction, too.

$$
\begin{gathered}
f_{b}=R_{i}^{2} / 90, \\
f_{b}=0.6 R_{i} /-7 \\
f_{b}=0.75 R_{i} /-16 \\
f_{b}=R_{i}^{2} / 110
\end{gathered}
$$

where $f_{b}$ is the compressive strength of the brick in $\mathrm{N} / \mathrm{mm}^{2}$, and $R_{i}$ is the rebound index obtained by Schmidt hammer, type N.

Figure 16 shows the change of the compressive strength in the function of the rebound number according to the different equations (10), (6), (7) and (8). It is interesting to note that an orthotropy of the compressive strength of the brick can be observed in directions $\mathrm{B}$ and $\mathrm{C}$ according to this type of measuring. The range of the mean value of the rebound number determined by 9 rebound index on each sample was between 42 and 50 .

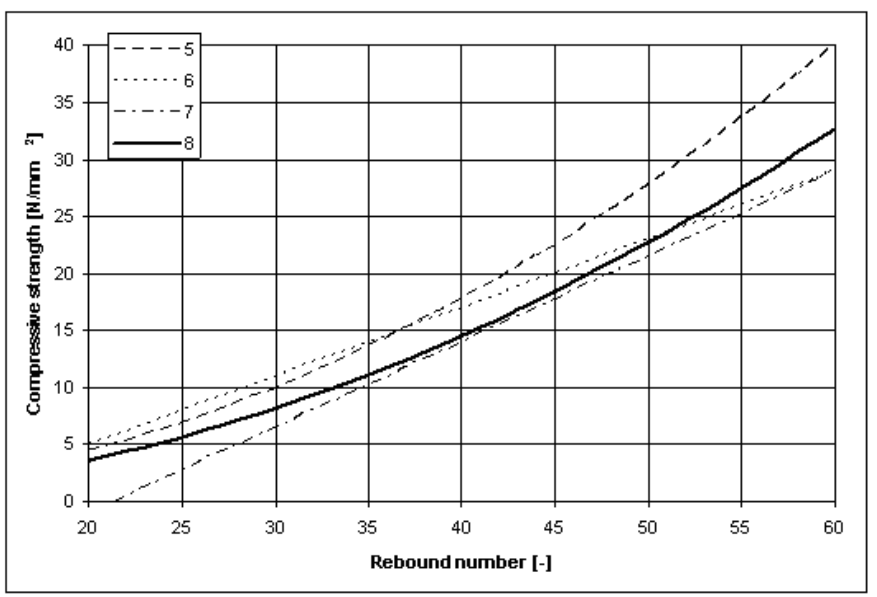

Fig. 16. Comparison of the relationship of $[11-13]$ and [14]

If the normalised mean compressive strength of the brick in loading direction $\mathrm{A}$ amounts to $20.0-25.0 \mathrm{~N} / \mathrm{mm}^{2}$, then the normalized mean compressive strength in direction $\mathrm{B}$ is 14.1$17.7 \mathrm{~N} / \mathrm{mm}^{2}$, in direction $\mathrm{C}$ it is $16.8-21.0 \mathrm{~N} / \mathrm{mm}^{2}$, as it was determined in Table 2. The normalized mean compressive strength from the cubic test and from the standard compressive tests are shown in Table 7. The last four columns present the results of the Schmidt hammer test, calculated from (10), (6), (7) and (8), respectively.

Table 7 shows that the equations (6), (7) and (8) is applicable in order to determine the normalized mean compressive strength in the direction A. If the normalized mean compressive strength has to be determined the relationships of the rebound number and compressive strength need to be modified.

It can be suggested that for the Schmidt hammer tests, in case of this brick, in case of $1.33 \mathrm{~N} / \mathrm{mm}^{2}$ hold-down stress of the specimen, in case of horizontal beating direction, that the relationship between the rebound index and the normalized compressive strength in direction $\mathrm{B}$ is:

$$
f_{b}=R_{i}^{2} / 160
$$

in the direction $\mathrm{C}$ :

$$
f_{b}=R_{i}^{2} / 130,
$$

where $f_{b}$ is the normalized mean compressive strength of the brick, and $R_{i}$ is the rebound index. To get the compressive strength of the loading direction A from the B and $\mathrm{C}$ directional beating, the normalized mean compressive strength of the unit in the direction B is suggested multiplying by 1.42 and in case of direction $\mathrm{C}$ by 1.19. Testing directions $\mathrm{B}$ or $\mathrm{C}$ and applying the formulae of (7) and (8), the A-directional normalized mean compressive strength can be obtained safely.

\section{Determination of the Young's modulus of the brick}

The Young's modulus of the brick was measured by two types of methods: by strain gauges, to avoid the restraint effect of the platens and by measuring the compression of the full size samples. In the first case, the strain gauges were glued on the cleaned surface of cylindrical samples. Three vertical strain gauges were put on every sample with $120^{\circ}$ offset. The results of the measurement are shown in Figure 17 signed with cylinder $\mathrm{A}, \mathrm{B}$ and $\mathrm{C}$ in each direction.

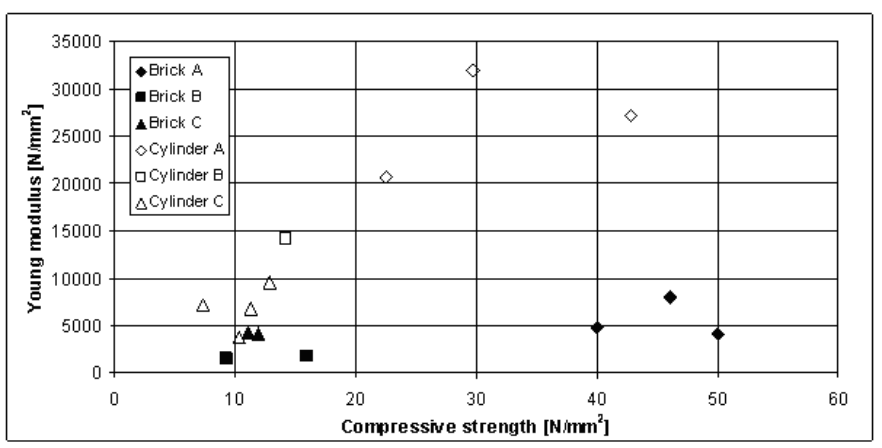

Fig. 17. Young's modulus in function of the compressive strength

In case of testing the full size bricks, the vertical compression of the specimens was measured by an inductive transducer 
Tab. 7. Mean values of compressive strength (rebound test using Schmidt hammer, type $\mathrm{N}$ - standard compressive test)

\begin{tabular}{|c|c|c|c|c|c|}
\hline \multirow[b]{2}{*}{ Directions } & \multicolumn{5}{|c|}{ Normalized mean compressive strength $\left[\mathrm{N} / \mathrm{mm}^{2}\right]$} \\
\hline & $\begin{array}{c}\text { Standard } \\
\text { compressive test } \\
\text { on cubic samples }\end{array}$ & $\begin{array}{c}\text { Schmidt test } \\
\text { evaluated acc. to } \\
10\end{array}$ & $\begin{array}{c}\text { Schmidt test } \\
\text { evaluated acc. to } \\
6\end{array}$ & $\begin{array}{c}\text { Schmidt test } \\
\text { evaluated acc. to } \\
7\end{array}$ & $\begin{array}{c}\text { Schmidt test } \\
\text { evaluated acc. to } \\
8\end{array}$ \\
\hline A & $20.0-25.0$ & - & - & - & - \\
\hline B & 14.1-17.7 & 24.8 & 21.36 & 19.45 & 20.3 \\
\hline C & $16.8-21.0$ & 24.2 & 21.00 & 19.00 & 19.8 \\
\hline
\end{tabular}

between the restraint platens. The results of the full brick are shown in Figure 17, as well. Compressive strengths presented are the measured values on each specimen. The Young's moduluses are calculated from the slope of the stress-strain relationship, from the $1 / 3-2 / 3$ of the elastic part of the diagram.

It can be stated that the Young's modulus measured with strain gauges is at least 3 times higher than the Young's modulus of the brick. The reason of that could be that the strain gauges measured the compression of a length 10 or $20 \mathrm{~mm}$, which presents the deformation of the material itself. The deformation of the brick could be measured rather with measuring the compression between the platens. It is worth noting that the strain gauges measurements hardly take into account the effect of the cracks located in the brick that modify the behaviour. However, measuring the compression of the brick itself is not the best method to determine the Young's modulus because of the support effect along the loading platen due to friction. Young's moduluses of the brick in the different directions are shown in the function of the normalized mean compressive strength, determined in Table 7 in Figure 18. It shows that the linearity in the different testing directions exists.

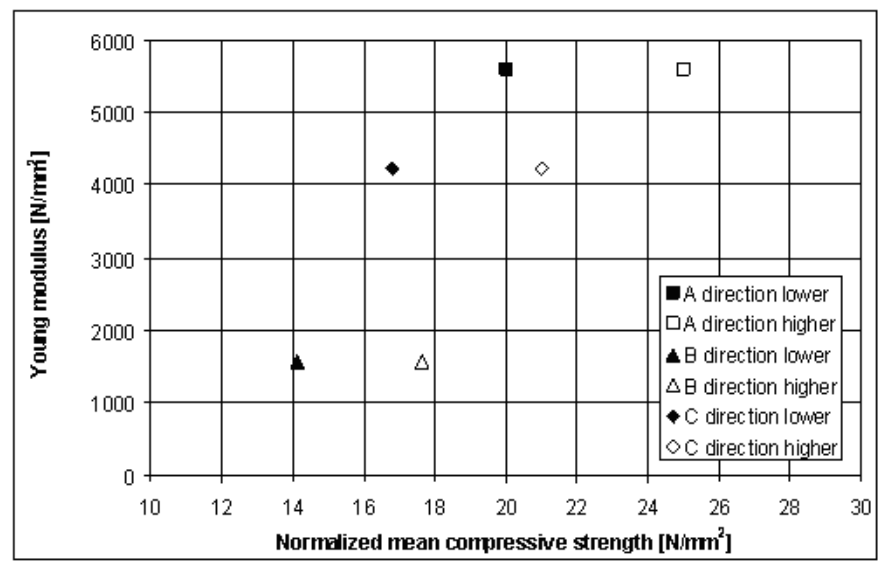

Fig. 18. Normalized mean compressive strength in function of the Young's modulus from Table 7

Figure 19 presents the behaviour of the brick in direction $\mathrm{C}$ with a loaded area of ca. $7800 \mathrm{~mm}^{2}$. A force-displacement diagram is shown that reflects the compressing softening behaviour of the brick that is hard to be measured.

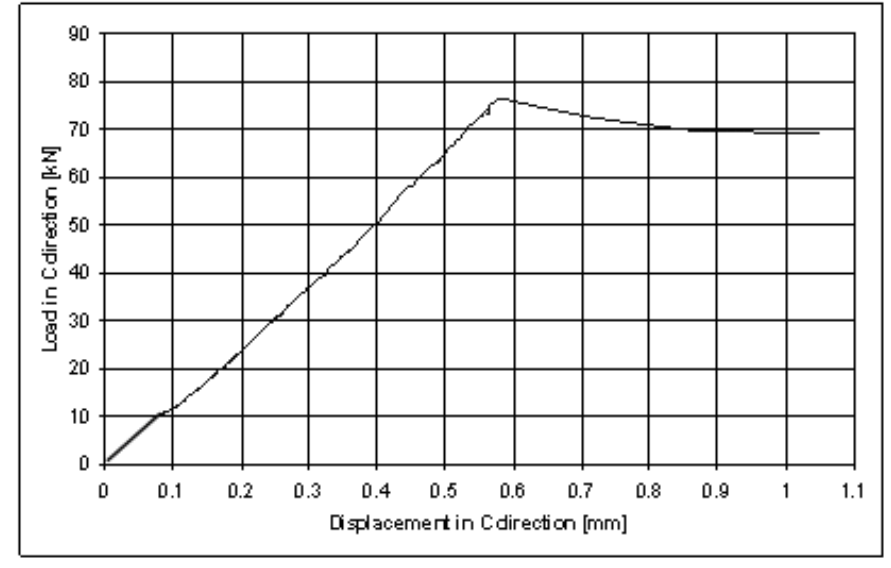

Fig. 19. Force-displacement diagram for direction $\mathrm{C}$

\section{Conclusions}

The novelty of the paper is a comprehensive experimental investigation of the compressive strength of one type of brick using more than 100 brick specimens. The effect of the type of the sampling, the surface, the height, the width and the length of the specimen were investigated.

In case of the investigated solid, fired clay brick a clear orthotropy was found. The reason of the orthotropy is assumed to exist due to the production technology. According to the orthotropy in the compressive strength and the Young's modulus, three characteristic directions were defined that corresponds to the direction of the manufacturing. Every relationship that was defined could be considered true only in the case when the ratio between the compressive strength in the three directions does not depend on the size of the specimen.

After investigating the smallest and the biggest specimen that could be reasonably obtained from this brick, correlations were found for the height, the width, the loaded area of the specimens and the compressive strength. It was determined that the height of the specimen has the biggest effect on the compressive strength. The orthotropy (the direction of the loading) has the same order of effect on the compressive strength as the geometry of the specimen has. An optimal loading surface was determined that results the maximal compressive strength.

A method was determined that makes possible to estimate the normalized mean compressive strength of the brick independent from the type of the sample (drilled, cut or whole brick). The size and shape of the specimen is not restricted, the normalized 
compressive strength can be evaluated from every type of sample according to the equations that were presented.

A modified calculation method for measuring the compressive strength by an N-type Schmidt hammer was suggested for this type of brick in order to receive directly the normalized mean compressive strength. Two types of methods were carried out for measuring the Young's modulus of the brick. A clear linearity was found between the Young's modulus and the compressive strength in each direction. Orthotropy was determined in the Young's moduluses in the defined three directions, too.

It is proposed to control the applicability of the correspondence of the equations for other types of bricks of other manufacturers. In case of bricks with vertical voids, it is suggested to control the load bearing capacity of the other 2 directions.

\section{References}

1 MSZ EN 772-1:2000, Methods of test masonry units Part 1: Determination of the compressive strength, 2000. Hungarian Standard.

2 MSZ EN 1996-1-1:2006, Eurocode 6: Design of masonry structures Part 11: General rules for reinforced and unreinforced masonry structures, 2006. Hungarian Standard.

3 Fódi A, Bódi I, Comparison of shear behaviour of masonry walls with and without reinforcement, Pollack Periodica 5 (2010), no. 13, 71-82, DOI 10.1556/Pollack.5.2010.3.7.

4 Fódi A, Bódi I, Experimental Investigation of solid masonry walls reinforced in different directions, The Eighth International Masonry Conference (Dresden, November 2010, July 7), Masonry (11) Proceedings of the Eighth International Masonry Conference, Vol. 1, Alinea Digitaldruck, Dresden, 2010, pp. 843-852.

5 McKenzie WMC, Design of structural masonry, Palgrave, New York, 2001.

6 Subasic CA, Borchelt JG, Clay and shale brick material properties - a statistical report, The 6th North American Masonry Conference, Proceedings of the 6th North American Masonry Conference, The Masonry Society, Boulder, CO, 1993, pp. 12-. in: Technical Notes 3A - Brick Masonry Material Properties, Technical notes on brick construction, 1992, www.gobrick.com.

7 Pate K, Noble W, Stress-strain relationship in heavy clay products, Mechanical properties of non-metallic brittle materials, Butterworth, London, 1958, pp. 210-216. in: Blight GE, Calculated Load bearing brickwork, Technical Publications, 2009, www.claybrick.org.za.

8 D'Ayala DF, Numerical modelling of masonry structures reinforced or repaired, Computer Methods in Structural Masonry (Pande N G, Middleton J, Kralj B, eds.), Routledge, 1998, pp. 161-168.

9 Völgyi I, Farkas Gy, Nehme S G, Concrete strength tendency in the wall of cylindrical spun-cast concrete elements, Periodica Polytechnica, Civil Engineering 54/1 (2010), 23-30, DOI 10.3311/pp.ci.2010-1.03.

10 Szalai K, Windisch A, Újhelyi J, Erdélyi A, Halász I, Roknich Gy, Strobl A, The quality control of concrete, Szabványkiadó, Budapest, 1982.

11 MI 15011-1988, Technical directive, 1988. publisher: Magyar Szabványügyi Hivatal.

12 Dulácska E, Book of structural engineering, Bertelsman kiadó, Budapest, 2001.

13 Dulácska E, Józsa Zs, Borosnyói A, Investigation of the compressive strength of the brick by Schmidt hammer, Eurocode 6 - Masonry Structures (Budapest, 2001), Proceedings of the Eurocode 6 - Masonry Structures (Balázs L Gy, ed.), Építésügyi Minőségellenőrző Innovációs KözhasznĂş Társaság, 2001, pp. 129-132.

14 Dulácska E, The reconstruction and diagnostic of load bearing elements of buildings, Budapest University of Technology and Economics, Budapest, 2008. Lecture notes. 